\title{
Assessing the effectiveness of synthetic and biologic disease-modifying antirheumatic drugs in psoriatic arthritis - a systematic review
}

This article was published in the following Dove Press journal:

Psoriasis: Targets and Therapy

12 May 2015

Number of times this article has been viewed

\section{Gabrielle H Kingsley David L Scott}

Rheumatology Unit, Kings College London, London, UK
Correspondence: Gabrielle H Kingsley Rheumatology Unit, Kings College London, Weston Education Centre, 10 Cutcombe Road, London SE5 9RS, UK Tel +44207848520I

Email gabrielle.kingsley@kcl.ac.uk
Background: Psoriatic arthritis is an inflammatory arthritis the primary manifestations of which are locomotor and skin disease. Although a number of guidelines have been published citing strategies for reducing disease progression, the evidence base for disease-modifying agents is unclear. This forms the focus of this systematic review.

Methods: The systematic review was undertaken according to the Preferred Reporting Items for Systematic Reviews and Meta-Analyses 2009 checklist. We selected randomized controlled trials (RCTs) that looked at the impact of interventions with disease-modifying agents, either synthetic drugs or biologics on musculoskeletal outcomes, notably American College of Rheumatology 20 percent responders. Results were analyzed using Review Manager 5.1.6 (Cochrane Collaboration, Oxford, UK). Whilst our primary focus was on published trials, we also looked at new trials presented in abstract form in 2013-2014 that were not yet published to avoid omitting important and up-to-date information on developing treatments.

Results: Our in-depth analysis included 28 trials overall enrolling 5,177 patients published between the 1980s and now as well as limited analysis of some studies in abstract form as described earlier. The most frequently available locomotor outcome measure was the American College of Rheumatology 20 percent responders. The risk ratio for achieving an American College of Rheumatology 20 percent responders response was positive in favor of treatment (risk ratio 2.30; 95\% confidence interval 1.78-2.96); however, there was evidence of considerable heterogeneity between trials. Overall randomized controlled trials of established synthetic disease-modifying agents were largely negative (methotrexate, ciclosporin and sulfasalazine) though leflunomide showed a small positive effect. A new synthetic agent, apremilast, did show a positive benefit. For biologics, TNF inhibitors already licensed for use were effective and similar benefits were seen with newer agents including ustekinumab, secukinumab, brodalumab, and abatacept, although the latter did not impact on skin problems. Important limitations of the systematic review included, first, the fact that for many agents there were little data and, second, much of the recent data for newer biologics were only available in abstract form.

Conclusion: Conventional disease-modifying agents, with the possible exception of leflunomide, do not show clear evidence of disease-modifying effects in psoriatic arthritis, though a newer synthetic disease-modifying agents, apremilast, appears more effective. Biologic agents appear more beneficial, although more evidence is required for newer agents. This review suggests that it may be necessary to review existing national and international management guidelines for psoriatic arthritis.

Keywords: psoriatic arthritis, disease-modifying antirheumatic drugs, biologics

\section{Introduction}

Psoriatic arthritis (PsA) is an inflammatory arthritis usually occurring in patients who already have psoriasis ${ }^{1,2}$ although $15 \%-20 \%$ of patients develop arthritis before 
skin psoriasis. The pattern of joint involvement varies both between patients and over time; it can include spondylarthopathy, peripheral arthritis (oligoarticular or polyarticular), and a destructive variant, arthritis mutilans. PsA is a multi-system disease. As well as affecting the joints, tendons, and skin in virtually all patients, there is a higher incidence of depression than in the general population ${ }^{3}$ and an increased morbidity and mortality from cardiovascular disease. ${ }^{4}$

Prevalence estimates vary, but the disease affects approximately $0.04 \%-0.1 \%$ of the general adult population and $20 \%-30 \%$ (range $6 \%-42 \%$ ) of patients with psoriasis. The peak age of onset is in the fourth and fifth decades affecting both sexes equally. PsA usually develops at the onset of psoriasis or within five to seven years of onset. ${ }^{5,6}$

Initially, treatment focused on symptom relief using interventions such as analgesics and nonsteroidal anti-inflammatory drugs, physiotherapy, exercise programs, and local therapies such as intra-articular steroids. In contrast, current treatment, in all but the mildest of cases, aims to control the underlying inflammatory process, and hence, reduces disease activity and induces remission. It is anticipated that this approach will prevent disability and systemic involvement and improve overall outcomes.

The agents that are likely to have the biggest impact on controlling the underlying disease are systemic diseasemodifying agents (DMARDs). Standard synthetic DMARDs, notably sulfasalazine, methotrexate, ciclosporin, and leflunomide, have been in use in PsA for many years and play a major role in national and international guidelines though their efficacy remains open to question.

Recent studies have focused more on biologic DMARDs. These have included TNF inhibitors (infliximab, etanercept, adalimumab, certolizumab and golimumab); ustekinumab, which targets interleukin (IL)-12 and IL-23; abatacept; secukinumab, which is a novel selective IL-17A inhibitor; and brodalumab, which is a novel IL-17 receptor blocker. A novel synthetic agent, apremilast, has also been recently examined; it inhibits production of multiple pro-inflammatory cytokines and is a specific inhibitor of phosphodiesterase E4.

In recent years guidelines produced for the management of PsA by the European League against Rheumatism, the British Society for Rheumatology, NICE (National Institute for Health and Clinical Excellence) and the Scottish Guideline Network have included recommendations about biologic DMARD therapy or both biologic and synthetic DMARD therapy. ${ }^{7-12}$ Much of the recommendations on older synthetic DMARDs are based substantially on expert opinion, as there are relatively limited research data to support their use. There have also been several systematic reviews of different treatment options, ${ }^{13-24}$ though these have not been able to include the large number of new trials in the field.

Our new systematic review is designed to provide greater clarity about the evidence base for DMARDs in PsA. It examines both licensed and novel biologic and synthetic DMARDs, using only evidence from randomized controlled trials. In addition, to avoid confusion, it focuses only on trials with a primary locomotor endpoint as opposed to skin, cardiovascular, or mental health outcomes. As this is a developing area, we undertook both a conventional systematic review and an analysis of data presented at recent international meetings but not yet published in peer-reviewed journals.

\section{Methods \\ Search strategy}

The systematic review was carried out according to the Preferred Reporting Items for Systematic Reviews and MetaAnalyses 2009 checklist. ${ }^{25}$ Initially, we searched PubMed using the term "psoriatic arthritis" with the additional filter of "article type - clinical trial" from 1975 to 2014. We subsequently searched Ovid Medline, EMBASE, and the Cochrane database using these terms to ensure no trials were overlooked. The titles and abstracts were then hand-searched by both authors independently. When there were any doubts regarding the eligibility of a study, the study was discussed between reviewers until agreement was reached.

\section{Selection criteria}

We selected trials that assessed the effects of systemic DMARDs, which were either conventional synthetic drugs or were biologic agents, on musculoskeletal outcomes. The inclusion and exclusion criteria for entering studies into the review are summarized in Table 1. Finally, we excluded trials that were not published in English.

\section{Assessing the risk of bias}

The risk of bias was judged using criteria recommended by Viswanathan et al. ${ }^{27}$

\section{Outcome measures}

We collected data on three dichotomous outcomes. They were the American College of Rheumatology 20 percent responders (ACR20), the psoriatic arthritis response criteria (PsARC), and withdrawals from treatment for toxicity. These were used to calculate random effects risk ratios with $95 \%$ confidence interval (CI).

When trials did not report ACR20 or PsARC outcomes, we undertook a narrative evaluation of their main findings. 
Table I Selection criteria for trials in review

\begin{tabular}{|c|c|}
\hline Inclusion criteria & Exclusion criteria \\
\hline $\begin{array}{l}\text { Randomized controlled trial against placebo or two agents } \\
\text { against each other, which for synthetic DMARDs lasted } \\
\text { at least } 12 \text { weeks }\end{array}$ & $\begin{array}{l}\text { All other study designs including cross-sectional observational, case series/cohort/ } \\
\text { registry, open-label }\end{array}$ \\
\hline $\begin{array}{l}\text { Primary outcome is related to clinical assessment of locomotor } \\
\text { system (eg, symptoms, joint score/DAS, HAQ) }\end{array}$ & $\begin{array}{l}\text { All other clinical outcomes (including skin, eyes, CVS, depression/psych/quality } \\
\text { of life) and nonclinical outcomes (eg, imaging, biomarkers) }\end{array}$ \\
\hline $\begin{array}{l}\text { Primary intervention is a systemic disease-modifying agent, } \\
\text { either DMARD or biologic }\end{array}$ & $\begin{array}{l}\text { All other therapeutic agents including: } \\
\text { - Local treatment (eg, IA steroids, IA yttrium, brachytherapy, IA biologics/ } \\
\text { DMARDs, botulinum) } \\
\text { - Other drugs (nonsteroidal anti-inflammatory drugs) } \\
\text { - Complementary therapy (eg, primrose oil) } \\
\text { - Other immunotherapy (eg, leishmania or mycobacterial antigens) } \\
\text { - Physiotherapy (including balneotherapy, interferential) or education } \\
\text { - Surgery }\end{array}$ \\
\hline $\begin{array}{l}\text { Patients in study met diagnostic criteria for PsA, including } \\
\text { criteria from CASPAR, }{ }^{26} \text { Moll and Wright,' } \text { and others unique } \\
\text { to the trials }\end{array}$ & $\begin{array}{l}\text { Some or all patients in the study did not meet PsA criteria and had other forms } \\
\text { of spondyloarthritis }\end{array}$ \\
\hline
\end{tabular}

Abbreviations: PsA, psoriatic arthritis; DMARDs, disease-modifying agents; CVS, cardiovascular system; DAS, Disease activity score; HAQ, Health Assessment Questionnaire; IA, intra-articular.

\section{Statistical analysis}

Results were analyzed using Review Manager 5.1.6 (Cochrane Collaboration, Oxford, UK). The random effects model based on DerSimonian and Laird's method ${ }^{28}$ was used to estimate the pooled effect sizes; this gives more equal weighting to studies of different precision in comparison with a simple inverse variance-weighted approach, thus accommodating between study heterogeneity. For all meta-analyses, we performed Cochran's chi-squared test to assess between study heterogeneity and quantified $I^{2}$ statistics. ${ }^{29,30}$ We considered a $P$-value $<0.05$ as statistically significant.

In randomized controlled trials with two or more treatment doses, the treatment arm with the best outcome was used.

\section{Assessment of new trials presented in abstract form}

There have been many new trials in this field with data having been presented in abstract form prior to full publication. We therefore completed the review by undertaking a narrative description of new trials published as meeting abstracts presented at the American College of Rheumatology in 2013-14, which is a major annual international meeting in the field. We focused on trials that enrolled patients with PsA, evaluated treatment with synthetic or biologic DMARDs, and assessed locomotor outcomes.

\section{Results}

\section{Trials}

The preliminary search identified 480 papers: 40 were potentially relevant trials and were selected for full-text review (Figure 1). Twelve studies were excluded for the following reasons: two did not evaluate PsA and focused on psoriasis, one was not a disease-modifying drug (colchicine), four were for drugs that had been withdrawn for concerns about toxicity, one was of too short duration to define an effect with the agent being tested (only two months), one compared two doses of one drug (etanercept), one was a comparison of co-therapies given with etanercept, and two were not in English.

Twenty eight trials were included ${ }^{31-58}$ and their characteristics are summarized in Table 2. The trials randomized between 30 and 615 patients. Overall they enrolled 5,177 patients. One trial was published in the 1980 s, five in the 1990s, 12 from 2000 to 2009, and ten after 2010. Most trials compared one active treatment with placebo; one trial by Fraser et al ${ }^{39}$ compared ciclosporin combined with methotrexate against methotrexate monotherapy.

Sixteen trials used ACR20 responders as the primary outcome measure, four used the PsARC as the primary outcome measure, two had tenderness and pain as their primary outcome, and six historic trials had no primary outcome. Nineteen trials used three active joints (three tender or three tender and three swollen joints) as a minimum entry criterion, five trials used five active joints, two trials used one active joint, and two trials had no joint count entry criterion for entry. Eight trials used an elevated erythrocyte sedimentation rate and/or C-reactive protein as an entry criterion.

Eleven trials studied licensed synthetic DMARDs, 13 trials studied licensed biologic DMARDs, two trials studied novel synthetic DMARDs, and two trials studied novel 


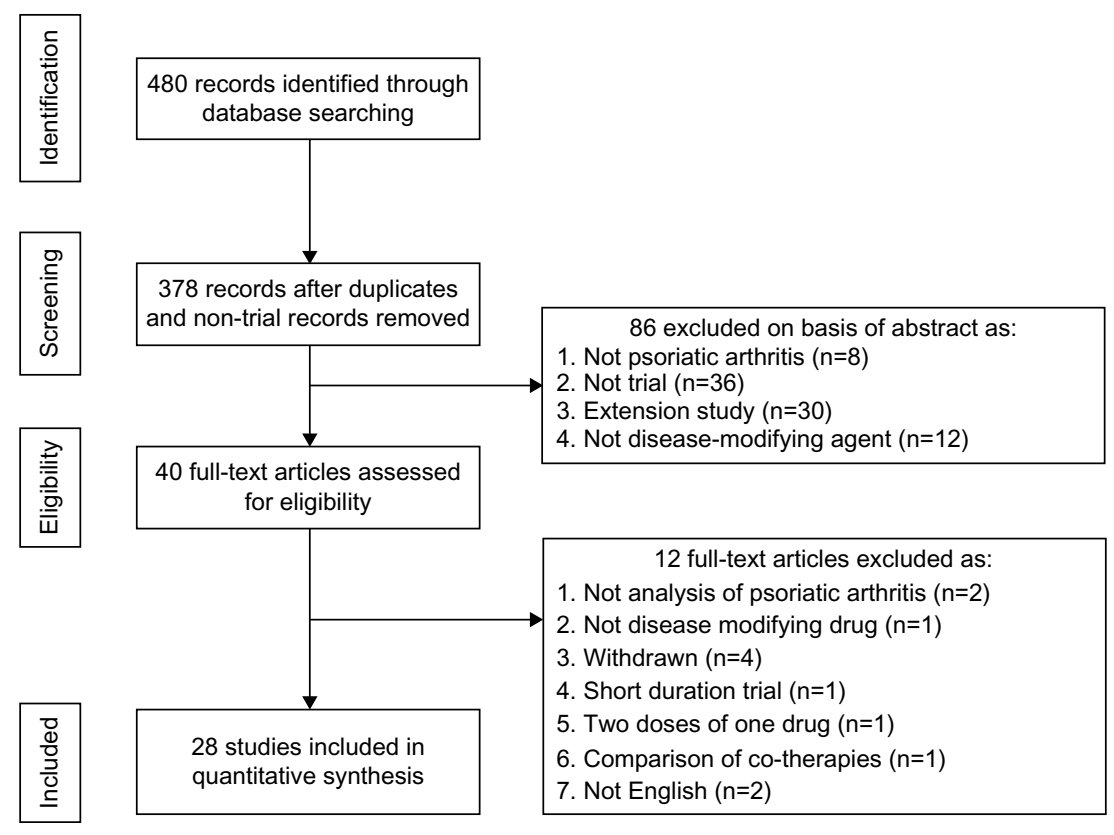

Figure I Search strategy.

biologic DMARDs. Trials lasted from 12 to 52 weeks; the mean duration was 29 weeks. The primary endpoint was measured from 6 to 52 weeks; the mean time was 19 weeks.

The trials enrolled patients of mean age 47 years (range 26-52) and mean disease duration 7 years (range of disease duration is from less than one year to 14 years). Most trials enrolled an excess of males.

\section{Overall benefits}

ACR20 responses were most often reported; they were available in 21 comparisons of different DMARDs from 20 trials. Overall, the risk ratio of achieving an ACR20 response was positive in favor of treatment (risk ratio 2.57; 95\% CI 2.05, 3.23); these findings are summarized in Figure 2. There was evidence of considerable heterogeneity between trials $\left(I^{2}=74 \% ; \chi^{2}=77.97, P<0.00001\right)$. Seventeen of the 21 comparisons were positive. Three of the four negative comparisons involved established synthetic DMARDs (ciclosporin, methotrexate, and sulfasalazine), and three of them involved small sample sizes (under 100 randomized patients).

PsARC responses were reported in eleven comparisons of different DMARDs from eleven trials. Overall, the risk ratio of achieving a PsARC response was positive in favor of treatment (risk ratio 2.22; 95\% CI 1.79, 2.75). There was evidence of considerable heterogeneity between trials $\left(I^{2}=68 \% ; \chi^{2}=31.6\right.$, $P=0.0005)$. All the comparisons were positive, though one trial of sulfasalazine had only borderline positivity.

\section{Synthetic disease-modifying drugs}

Thirteen trials studied synthetic DMARDs. One evaluated injectable gold, four evaluated sulfasalazine, one evaluated sulfasalazine and ciclosporin, one evaluated ciclosporin, three evaluated methotrexate, one evaluated leflunomide, and two evaluated apremilast.

Five of these trials reported ACR20 responses (including the trial reporting findings with both sulfasalazine and ciclosporin). There was an overall benefit for DMARDs (risk ratio 1.81 ; $95 \%$ CI 1.29, 2.55). However, in three comparisons with ciclosporin, methotrexate, and sulfasalazine, there was no statistical benefit for DMARDs. Three of these trials reported PsARC outcomes. There was a weak overall benefit for DMARDs (risk ratio 1.61; 95\% CI 1.21, 2.13). Many trials did not report summary outcomes such as ACR20 and PsARC and only gave changes in individual measures. These were mainly historic studies undertaken before outcome measures were standardized.

There were variable findings with individual drugs. One of the four trials evaluating sulfasalazine reported considerable benefit and, although it did not use any conventional overall standardized assessment, 12/14 (86\%) patients receiving sulfasalazine had some benefit compared with 4/14 (28\%) of controls. Two trials reported some benefits; in one there was a borderline improvement in PsARC with sulfasalazine and the other showed more changes with sulfasalazine than placebo. The fourth trial showed only a significant benefit on pain levels with sulfasalazine; all other variables showed 


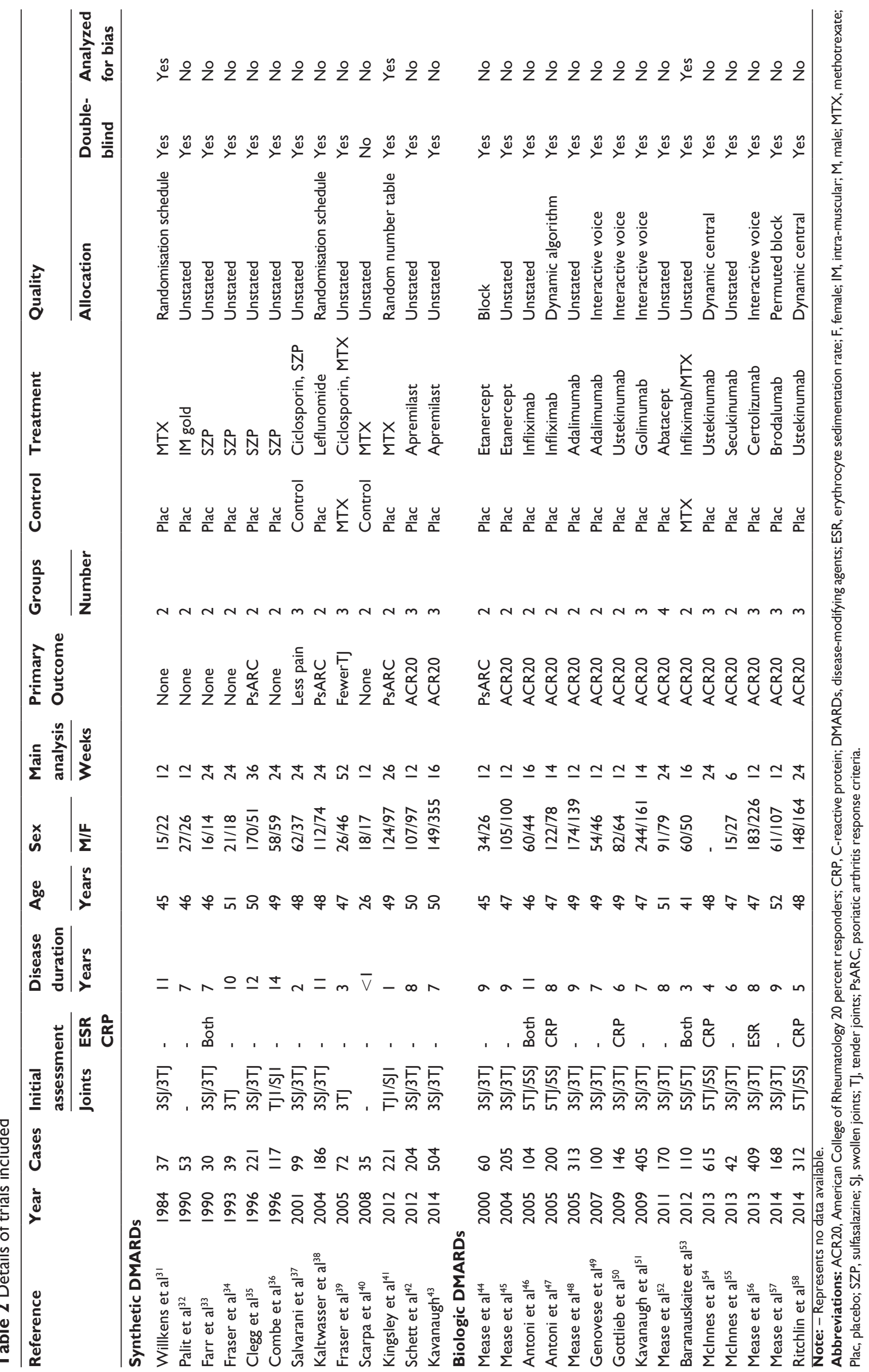




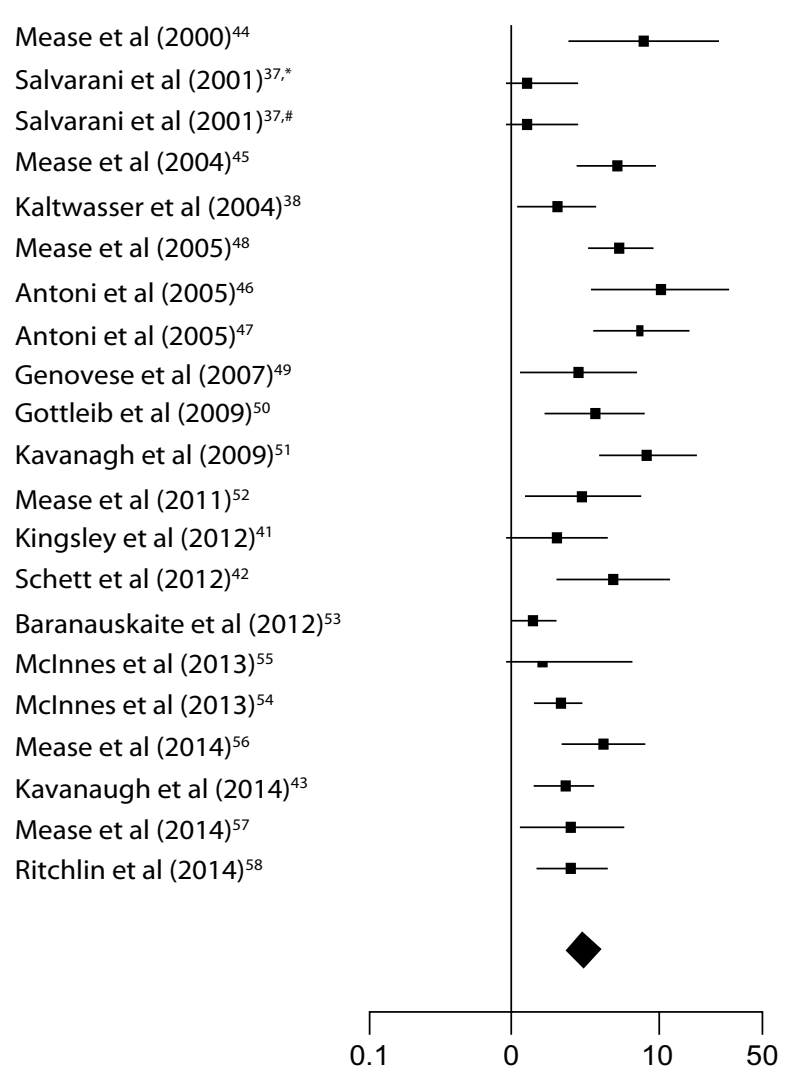

Favors control Favors experimental

Figure 2 Relative risks of American College of Rheumatology 20 percent responders.

Notes: *First arm of this study: ciclosporin. \#Second arm of this study: sulfazalazine.

similar changes with active and placebo therapy. The single trial involving injectable gold showed greater initial changes with gold, but by 24 weeks, active and placebo treatments were indistinguishable across all clinical measures. One of the three trials involving methotrexate reported greater falls in tender and swollen joint counts at 12 weeks with active treatment; the other two trials were essentially negative, though both identified greater changes in global assessments with methotrexate. One of the two trials of ciclosporin found significant benefits from treatment; the other, which involved adding ciclosporin to methotrexate was essentially negative. The only trial of leflunomide provided strongly positive findings. Finally, both trials involving apremilast were positive; combining these trials showed the risk ratio for an ACR20 response to be significant (risk ratio 2.52; $95 \%$ CI 1.40, 4.53).

\section{Biological disease-modifying drugs}

Fifteen trials have reported results with biologic DMARDs. Nine evaluated TNF inhibitors, three evaluated ustekinumab, one evaluated abatacept, one evaluated secukinumab, and one brodalimumab.

All these trials reported ACR20 responses. Overall, these were positive (risk ratio 2.98 ; $95 \%$ CI $2.22,4.01$ ). In the nine trials of TNF inhibitors, ACR20 responses occurred with risk ratio $3.63(95 \%$ CI 2.19, 6.03). In the three trials of ustekinumab, they occurred with risk ratio 2.06 (95\% CI 1.64, 2.59). The other trials of individual biologics had variable risk ratios; with abatacept the risk ratio was 2.49 (95\% CI $1.23,5.04)$, with secukinumab the risk ratio was $1.50(95 \%$ CI $0.48,4.68$ ) and with brodalimumab the risk ratio was 2.16 (95\% CI 1.31, 4.13).

Seven of these trials reported PsARC responses; these were also positive (risk ratio 2.64 ; 95\% CI 2.29, 3.05).

\section{Recent trials published in abstract form}

Several new trials have been presented at recent international meetings in abstract form. We have included these as a secondary assessment as they could change the assessment of newly developed treatments. Reviewing international rheumatology meetings in 2013 and 2014 identified six trials that enrolled 2,684 patients. ${ }^{59-64}$ Three trials compared apremilast to placebo therapy, ${ }^{59-61}$ two trials compared secukinumab to placebo therapy, ${ }^{62,63}$ and one trial compared clazakizumab to placebo therapy ${ }^{64} \mathrm{All}$ trials used ACR20 responses as their primary outcome measure, recorded from 16 to 24 weeks.

Overall, the six new trials gave positive results; the risk ratio for achieving an ACR20 response was 2.18 (95\% CI $1.68,2.82)$. With apremilast, the risk ratio in three trials was 1.97 (95\% CI 1.59, 2.45); with secukinumab in two trials, it was 3.09 (95\% CI 2.34, 4.07), and with the single trial of clazakizumab, it was 1.26 (95\% CI 0.72, 2.18).

Results from the five trials with apremilast (two full papers and three abstracts) and the three trials with secukinumab (one full paper and two abstracts) were combined. With apremilast, the risk ratio of achieving an ACR20 response was $2.10(95 \%$ CI 1.75, 2.51); there was little evidence of heterogeneity in the five trials $\left(I^{2}=0 \% ; \chi^{2}=3.68\right.$, $P=0.45)$. With secukinumab, the risk ratio of achieving an ACR20 response was 2.97 (95\% CI 2.27, 3.88); there was also little evidence of heterogeneity in the three trials $(R=0 \%$; $\chi^{2}=1.86, P=0.39$ ).

Finally, we compared ACR20 responders using full papers and published abstracts (Table 3). Risk ratios varied from less than 2 with long-standing synthetic DMARDs like sulfasalazine and methotrexate to over 3 with biologics like etanercept and golimumab. 
Table 3 Responses of American College of Rheumatology 20 percent responders for different drugs (including published abstracts)

\begin{tabular}{llll}
\hline Drug & Trials & $\begin{array}{l}\text { Risk } \\
\text { ratio }\end{array}$ & $\begin{array}{l}\text { 95\% confidence } \\
\text { intervals }\end{array}$ \\
\hline Sulfasalazine $^{37}$ & $\mathrm{I}$ & $\mathrm{I} .23$ & $0.67,2.28$ \\
Ciclosporin $^{37}$ & $\mathrm{I}$ & $\mathrm{I} .25$ & $0.69,2.28$ \\
Clazakizumab $^{64}$ & $\mathrm{I}$ & $\mathrm{I} .26$ & $0.72,2.18$ \\
Leflunomide $^{38}$ & $\mathrm{I}$ & $\mathrm{I} .8 \mathrm{I}$ & $\mathrm{I} .10,2.96$ \\
Methotrexate $^{41}$ & $\mathrm{I}$ & $\mathrm{I} .82$ & $0.97,3.40$ \\
Ustekinumab $^{50,54,58}$ & 3 & 2.06 & $\mathrm{I} .64,2.59$ \\
Apremilast $^{42,43,59-61}$ & 5 & 2.10 & $\mathrm{I} .75,2.5 \mathrm{I}$ \\
Brodalimumab $^{57}$ & $\mathrm{I}$ & 2.16 & $\mathrm{I} .13,4.13$ \\
Certolizumab $^{56}$ & $\mathrm{I}$ & 2.39 & $\mathrm{I} .72,3.32$ \\
Abatacept $^{52}$ & $\mathrm{I}$ & 2.49 & $\mathrm{I} .23,5.04$ \\
Secukinumab $^{55,62,63}$ & 3 & 2.97 & $2.27,3.88$ \\
Adalimumab $^{48,49}$ & 2 & $3.4 \mathrm{I}$ & $2.10,5.54$ \\
Infliximab $^{46,47,53}$ & 3 & $3.5 \mathrm{I}$ & $0.88,13.98$ \\
Etanercept $^{44,45}$ & 2 & 4.15 & $2.7 \mathrm{I}, 6.36$ \\
Golimumab $^{51}$ & $\mathrm{I}$ & 5.73 & $3.10,10.57$ \\
\hline
\end{tabular}

\section{Toxicity}

A range of toxicities occurred in the various trials. Comparing groups and trials by patients withdrawn from therapy for toxicity showed a small excess of toxicity with active treatment (risk ratio 1.49; 95\% CI 1.04, 2.13). Although trials differed in the numbers of patients withdrawn, there was no overall heterogeneity in toxicity withdrawals $\left(I^{2}=13 \%\right.$; $\chi^{2}=26.3, P=0.29$ ).

Comparing risks with synthetic DMARDs against biologic DMARDs showed the excess risk was with synthetic DMARDs alone (risk ratio 1.82, 95\% CI 1.14, 2.89, compared with risk ratio $1.11,95 \%$ CI $0.63,1.95)$. Some historic treatments, such as gold injections gave higher risks of adverse effects. There were insufficient data to make comparative judgments about modern synthetic DMARDs.

\section{Quality}

The quality of the trials varied. Modern trials were of higher quality than older ones. Most trials (25/28) were double blinded, but only 12 of these described their allocation procedure in detail. These descriptions suggested appropriate methods were used. Only 3/28 trials gave detailed consideration to potential analytical bias.

\section{Discussion}

The main message from this systematic review is that the standard medication used for PsA is of only limited efficacy but that newer biologic agents may offer a much higher level of efficacy. This differs significantly from the situation in rheumatoid arthritis, where a significant proportion of patients respond well to conventional DMARDs either as monotherapy or in combination, ${ }^{66}$ but resembles that seen in other spondyloarthropathies, notably ankylosing spondylitis. ${ }^{67}$ This conclusion is important for two main reasons. First, it suggests that treatment strategies cannot simply be adapted from rheumatoid arthritis to PsA as has been done in the past, and second, it brings into question the requirement of regulatory bodies and the suggestion of those issuing treatment guidance that medication that has not been shown to be effective in randomized trials must be used before patients can be offered medication, which has been proven to be effective. ${ }^{11,12}$ These conclusions are examined in more depth in the following sections.

\section{Conventional DMARDs and apremilast}

Sulfasalazine, ciclosporin, and methotrexate do not demonstrate efficacy in terms of true disease modification because studies examining disease-modifying outcome measures notably the ACR20 show 95\% CI below 1. Earlier trials demonstrated improvement in parameters including pain and tender joints, but these are more closely associated with symptom relief than true disease modification. Leflunomide demonstrated only a marginal benefit on the ACR2 0 with a risk ratio of 1.81 and a lower $95 \%$ CI of 1.1 . The novel nonbiologic DMARD, apremilast, had a better effect than these earlier nonbiologic DMARDs with a risk ratio for an ACR20 response of 1.98 (95\% CI 1.60, 2.43). However, this level of response is not a very major clinical advance on those seen with earlier nonbiologic agents.

\section{Biologic agents}

The standard biologics used in PsA are the TNF inhibitors. These are licensed in both the United States and Europe for this condition and show increased efficacy, as assessed by the ACR20 (Table 3) compared to the agents discussed earlier. In terms of comparison, adalimumab and etanercept seem to be similar but infliximab has a higher risk ratio; however, this may be a dose-related effect.

However, only just over half (58\%, range 39\%-79\%) of PsA patients respond to these agents, meaning that $42 \%$ need alternative treatments and some of the responders develop toxicity, so the advent of additional biologic agents is to be welcomed. These include existing and novel agents targeting a variety of pathways involved in the pathogenesis of PsA including the T cell costimulation pathway (abatacept), the IL-6 pathway (clazakisumab), the IL-12/23 pathway 
(ustekinumab), and the IL-17 pathway (secukinumab and brodalumab). Abatacept has a good effect on the ACR20 but limited benefit for the skin; clazakisumab also, does not help the skin but, unlike abatacept, has only a limited impact on the joints, as well.

Ustekinumab has proved successful in the treatment of psoriasis leading to a number of recent trials in PsA. Overall, for the ACR20 these studies have shown a risk ratio for efficacy of $2.06(95 \%$ CI 1.64, 2.59) similar to that for agents already in use such as etanercept and adalimumab; however, some studies recruited patients who failed TNF inhibitors so there may be efficacy in TNF inhibitor nonresponders. Treatment benefits are seen for at least 2 years and include improvement in locomotor and general manifestations including peripheral joints, entheses, spine, and fatigue. ${ }^{68-70}$ Pooled safety data over 2 years treatment with ustekinumab demonstrated that it was well tolerated with a similar safety profile to its use in psoriasis. ${ }^{71}$ With the preexisting good results in psoriasis, these results suggest that ustekinumab could be a useful addition to the treatment of PsA, especially for patients who do not respond to TNF inhibitors. However, in May 2014, NICE did not approve its use in PsA in the United Kingdom. ${ }^{72}$ NICE accepted that ustekinumab was effective compared to conventional drugs but noted a mixed treatment comparison (a method for comparing treatments in the absence of head-to-head trials) showed it was less effective than TNF inhibitors; these analyses differed from ours in using as endpoint, not ACR20, but Psoriasis Area Severity Index (which only measures skin disease) and PsARC (which is an unvalidated overall PsA measure). Although ustekinumab costs the same as other biologics ( $£ 10,000$ per annum), NICE's cost-effectiveness analyses suggested it exceeded their usual cut-off level of $£ 30,000$ per quality-adjusted lifeyear. It is unclear whether, subjected to the same analysis, TNF inhibitors would also be over this threshold but NICE made no comment on this. Further work is clearly needed; meanwhile, NICE suggest that TNF inhibitor failures should be given a different TNF inhibitor although the evidence for this approach is limited. One trial of certolizumab included patients previously treated with TNF inhibitors and found these patients also responded to the new biologic. ${ }^{56}$

Secukinumab is another biologic, effective in psoriasis, that could potentially be useful in PsA; however, much of the important data remain in abstract form. A single published trial showed a risk ratio for efficacy of 1.50 , but with such a broad 95\% CI (0.48-4.68), it is difficult to place much reliance on that data. However, an overall analysis, including trials from published abstracts, suggests a risk ratio of 2.97
(95\% CI 2.27-3.88). This is more effective than biologics impacting on other pathways, including ustekinumab, with the exception of infliximab (where the studies used a higher than usual dose) and abatacept (which does not benefit the skin). Interestingly, brodalumab, which affects the same IL-17 pathway, also has a good risk ratio for efficacy, although so far, there has been only a single trial. Further information suggests that secukinumab is effective and safe for up to 52 weeks, benefits quality of life, ${ }^{65}$ and importantly, inhibits radiographic progression, which is potentially crucial for impacting long-term disability. ${ }^{62,73}$ If the results for secukinumab are borne out by further analysis, it would potentially be a significant advance on current biologic treatments.

\section{Quality and bias}

We found the quality of the trials varied, with modern trials being of higher quality. Most trials did not describe any potential analytical bias. Many of the trials involved pharmaceutical sponsors, and there is evidence that this continues to influence trial reporting. ${ }^{74}$ However, as virtually all trials had some pharmaceutical involvement, even if this was only supplying treatments and placebos without cost, we have not been able to evaluate the impact of having no pharmaceutical involvement. Finally, as we have included trials published only in abstract form, we cannot fully identify the impact of publication bias in this particular field.

\section{Limitations}

This review is limited by the small number of studies of each agent, especially for conventional DMARDs, and for combination treatment, which has proved so successful in rheumatoid arthritis. One such study, using a treat-to-target strategy, ${ }^{75}$ has reported positive preliminary results ${ }^{76}$ and a final publication is awaited. Many of the earlier studies are of a relatively small size (reflecting the relative rarity of PsA compared, for example, to rheumatoid arthritis) and were undertaken before the importance of using clear standardized predetermined outcome measures was fully appreciated.

The description of the different agents we have studied as being "DMARDs" is open to some debate. Some experts believe this term should be limited to drugs that effect erosive joint damage, and there is incomplete evidence for any of these drugs having such an impact. Other experts consider the term indicates drugs, which help by tackling the causes of inflammation, and our use of the term DMARD reflects this latter approach.

The quality of the studies undertaken more recently for the newer agents is higher than earlier studies, which makes it 
easier to compare different treatments. However, these studies are almost entirely pharmaceutically driven, raising possible concerns over bias and selective reporting. Furthermore, many are still only reported in abstract form, meaning that they have not been subject to a full peer review.

Finally, our meta-analyses have focused on locomotor outcomes, but it is clear that PsA is a complex disease with multiple outcomes so that a single treatment pathway, as envisaged by existing national and international guidelines, may be less appropriate than an individualized approach.

\section{Outcomes in PsA and personalized medicine}

One complication when assessing treatment for PsA is the wide range of outcomes that need to be considered. Improving synovitis is only part of the story because, for many patients, there are other equally important musculoskeletal measures such as dactylitis, enthesitis, and for PsA subtypes associated with spondyloarthropathy, spinal inflammation. These were rarely specifically examined in earlier studies, though their response to treatment may differ from that of inflamed joints; more recent studies, including those for biologics have examined treatment efficacy for those tissues. ${ }^{8}$

Most patients with PsA would also want their treatment to be effective, not only for locomotor disease but also for the skin and nails. ${ }^{8}$ Again, there are agents that are particularly effective for the skin but have little impact on the joints. This review has primarily focused on locomotor manifestations, but it is important to recognize differential treatment responses, not only because it would be preferable to treat as many manifestations as possible with a single agent but also because more general outcome measures may be contaminated by lack of response in one organ system versus another. Qualityof-life measures are very sensitive to skin disease so treatments impacting on the skin (methotrexate, TNF inhibitors, apremilast, secukinumab) will appear to be more effective at improving quality of life than those that affect only the joints (ciclosporin, sulfasalazine, abatacept). Interestingly, methotrexate remains a widely used drug for PsA. There are likely to be several reasons for its use, including its benefits on the skin, its beneficial impact on global assessments, and its known effectiveness in rheumatoid arthritis. We consider it will continue to be widely used in the immediate future, but that in the longer term more effective agents that improve both the joints and the skin will be preferred.

$\mathrm{PsA}^{26}$ is also associated with a high risk of metabolic syndrome and a raised cardiovascular risk and so the impact of any treatment on this must also be considered. While this cannot easily be measured in short-term clinical trials, longer term postmarketing observational studies should be considered. In addition, it may be that agents such as tocilizumab, which have an adverse impact on cardiovascular risk through their effect on cholesterol, may not be an ideal choice.

Finally, treatments also need to impact on outcomes such as self-esteem and depression, which may be responsible for significant loss of quality-of-life and also lead to high alcohol intake and increased smoking, which in turn, worsen the cardiovascular risk. ${ }^{26}$

Taken together, this suggests that PsA is an eminently suitable candidate for an individualized approach where patients are offered treatment appropriate to the disease manifestations that they have.

\section{Disclosure}

Professor Kingsley has no conflicts of interest. In the last year, Professor Scott has received funding from Roche Limited, Napp Pharmaceuticals, and Eli Lilly and Company (under $£ 2,000)$; none of this was related to psoriatic arthritis or its treatment.

\section{References}

1. Moll JM, Wright V. Psoriatic arthritis. Semin Arthritis Rheum. 1973;3: 55-78.

2. Gladman DD, Antoni C, Mease P, Clegg DO, Nash P. Psoriatic arthritis: epidemiology, clinical features, course, and outcome. Ann Rheum Dis. 2005;64(Suppl 2):ii14-ii17.

3. McDonough E, Ayearst R, Eder L, et al. Depression and anxiety in psoriatic disease: prevalence and associated factors. J Rheumatol. 2014;41:887-896.

4. Ogdie A, Yu Y, Haynes K, et al. Risk of major cardiovascular events in patients with psoriatic arthritis, psoriasis and rheumatoid arthritis: a population-based cohort study. Ann Rheum Dis. 2015;74(2):326-332.

5. Shbeeb M, Uramoto KM, Gibson LE, O'Fallon WM, Gabriel SE. The epidemiology of psoriatic arthritis in Olmsted County, Minnesota, USA, 1982-1991. J Rheumatol. 2000;27:1247-1250.

6. Ogdie A, Langan S, Love T, et al. Prevalence and treatment patterns of psoriatic arthritis in the UK. Rheumatology. 2013;52:568-575.

7. Menter A, Gottlieb A, Feldman SR, et al. Guidelines of care for the management of psoriasis and psoriatic arthritis: section 1. Overview of psoriasis and guidelines of care for the treatment of psoriasis with biologics. J Am Acad Dermatol. 2008;58:826-850.

8. Ritchlin CT, Kavanaugh A, Gladman DD, et al. Treatment recommendations for psoriatic arthritis. Ann Rheum Dis. 2009;68:1387-1394.

9. SIGN. SIGN Guideline 121: Diagnosis and Management of Psoriasis and Psoriatic Arthritis in Adults; 2010. Available from: http://sign. ac.uk/guidelines/fulltext/121/contents.html. Accessed January 19, 2015.

10. NICE Technology Appraisals. Etanercept, Infliximab and Adalimumab for the Treatment of Psoriatic Arthritis; 2010. Available from: https:// www.nice.org.uk/guidance/ta199. Accessed January 19, 2015.

11. Gossec L, Smolen JS, Gaujoux-Viala C, et al; European League Against Rheumatism. European league against rheumatism recommendations for the management of psoriatic arthritis with pharmacological therapies. Ann Rheum Dis. 2012;71:4-12. 
12. Coates LC, Tillett W, Chandler D, et al. The 2012 BSR and BHPR guideline for the treatment of psoriatic arthritis with biologics. Rheumatology. 2013;52:1754-1757.

13. Jones G, Crotty M, Brooks P. Psoriatic arthritis: a quantitative overview of therapeutic options. The psoriatic arthritis meta-analysis study group. Br J Rheumatol. 1997;36:95-99.

14. Woolacott N, Bravo Vergel Y, Hawkins N, et al. Etanercept and infliximab for the treatment of psoriatic arthritis: a systematic review and economic evaluation. Health Technol Assess. 2006;10:1-239.

15. Kavanaugh AF, Ritchlin CT; GRAPPA Treatment Guideline Committee. Systematic review of treatments for psoriatic arthritis: an evidence based approach and basis for treatment guidelines. J Rheumatol. 2006;33:1417-1421.

16. Soriano ER, McHugh NJ. Therapies for peripheral joint disease in psoriatic arthritis. A systematic review. J Rheumatol. 2006;33:1422-1430.

17. Woolacott NF, Khadjesari ZC, Bruce IN, Riemsma RP. Etanercept and infliximab for the treatment of psoriatic arthritis: a systematic review. Clin Exp Rheumatol. 2006;24:587-593.

18. Ravindran V, Scott DL, Choy EH. A systematic review and metaanalysis of efficacy and toxicity of disease modifying anti-rheumatic drugs and biological agents for psoriatic arthritis. Ann Rheum Dis. 2008;67:855-859.

19. Lamel SA, Myer KA, Younes N, Zhou JA, Maibach H, Maibach HI. Placebo response in relation to clinical trial design: a systematic review and meta-analysis of randomized controlled trials for determining biologic efficacy in psoriasis treatment. Arch Dermatol Res. 2012;304: 707-717.

20. Pereda CA, Nishishinya MB, Martínez López JA, Carmona L; EvidenceBased Working Group of the Spanish Society of Rheumatology. Efficacy and safety of DMARDs in psoriatic arthritis: a systematic review. Clin Exp Rheumatol. 2012;30:282-289.

21. Ash Z, Gaujoux-Viala C, Gossec L, et al. A systematic literature review of drug therapies for the treatment of psoriatic arthritis: current evidence and meta-analysis informing the EULAR recommendations for the management of psoriatic arthritis. Ann Rheum Dis. 2012;71: 319-326.

22. Acosta Felquer ML, Coates LC, Soriano ER, et al. Drug therapies for peripheral joint disease in psoriatic arthritis: a systematic review. J Rheumatol. 2014;41:2277-2285.

23. Coates LC, Kavanaugh A, Ritchlin CT; GRAPPA Treatment Guideline Committee. Systematic review of treatments for psoriatic arthritis: 2014 update for the GRAPPA. J Rheumatol. 2014;41: 2273-2276.

24. Cawson MR, Mitchell SA, Knight C, et al. Systematic review, network meta-analysis and economic evaluation of biological therapy for the management of active psoriatic arthritis. BMC Musculoskelet Disord. 2014;15:26.

25. Moher D, Liberati A, Tetzlaff J, Altman DG; PRISMA Group. Preferred reporting items for systematic reviews and meta-analyses: the PRISMA statement. PLoS Med. 2009;6:e1000097.

26. Taylor W, Gladman D, Helliwell P, et al; CASPAR Study Group. Classification criteria for psoriatic arthritis: development of new criteria from a large international study. Arthritis Rheum. 2006;54:2665-2673.

27. Viswanathan M, Ansari MT, Berkman ND, et al. Assessing the Risk of Bias of Individual Studies in Systematic Reviews of Health Care Interventions. Methods Guide for Effectiveness and Comparative Effectiveness Reviews. Rockville, MD; 2008. Available from: http:// www.ncbi.nlm.nih.gov/books/NBK91433/?report=printable. Accessed January 19, 2015.

28. DerSimonian R, Laird N. Meta-analysis in clinical trials. Control Clin Trials. 1986;7:177-188.

29. Hardy RJ, Thompson SG. Detecting and describing heterogeneity in meta-analysis. Stat Med. 1998;17:841-856.

30. Higgins JP, Thompson SG, Deeks JJ, Altman DG. Measuring inconsistency in meta-analyses. BMJ. 2003;327:557-560.

31. Willkens RF, Williams HJ, Ward JR, et al. Randomized, double-blind, placebo controlled trial of low-dose pulse methotrexate in psoriatic arthritis. Arthritis Rheum. 1984;27:376-381.
32. Palit J, Hill J, Capell HA, et al. A multicentre double-blind comparison of auranofin, intramuscular gold thiomalate and placebo in patients with psoriatic arthritis. Br J Rheumatol. 1990;29:280-283.

33. Farr M, Kitas GD, Waterhouse L, Jubb R, Felix-Davies D, Bacon PA. Sulphasalazine in psoriatic arthritis: a double-blind placebo-controlled study. Br J Rheumatol. 1990;29:46-49.

34. Fraser SM, Hopkins R, Hunter JA, Neumann V, Capell HA, Bird HA. Sulphasalazine in the management of psoriatic arthritis. Br J Rheumatol. 1993;32:923-925.

35. Clegg DO, Reda DJ, Mejias E, et al. Comparison of sulfasalazine and placebo in the treatment of psoriatic arthritis. A Department of Veterans Affairs Cooperative Study. Arthritis Rheum. 1996;39: 2013-2020.

36. Combe B, Goupille P, Kuntz JL, Tebib J, Lioté F, Bregeon C. Sulphasalazine in psoriatic arthritis: a randomized, multicentre, placebocontrolled study. Br J Rheumatol. 1996;35:664-668.

37. Salvarani C, Macchioni P, Olivieri I, et al. A comparison of cyclosporine, sulfasalazine, and symptomatic therapy in the treatment of psoriatic arthritis. J Rheumatol. 2001;28:2274-2282.

38. Kaltwasser JP, Nash P, Gladman D, et al; Treatment of Psoriatic Arthritis Study Group. Efficacy and safety of leflunomide in the treatment of psoriatic arthritis and psoriasis: a multinational, doubleblind, randomized, placebo-controlled clinical trial. Arthritis Rheum. 2004;50:1939-1950.

39. Fraser AD, van Kuijk AW, Westhovens R, et al. A randomised, double blind, placebo controlled, multicentre trial of combination therapy with methotrexate plus ciclosporin in patients with active psoriatic arthritis. Ann Rheum Dis. 2005;64:859-864.

40. Scarpa R, Peluso R, Atteno M, et al. The effectiveness of a traditional therapeutical approach in early psoriatic arthritis: results of a pilot randomised 6-month trial with methotrexate. Clin Rheumatol. 2008;27: 823-826.

41. Kingsley GH, Kowalczyk A, Taylor H, et al. A randomized placebocontrolled trial of methotrexate in psoriatic arthritis. Rheumatology. 2012;51:1368-1377.

42. Schett G, Wollenhaupt J, Papp K, et al. Oral apremilast in the treatment of active psoriatic arthritis: results of a multicenter, randomized, double-blind, placebo-controlled study. Arthritis Rheum. 2012;64: 3156-3167.

43. Kavanaugh A, Mease PJ, Gomez-Reino JJ, et al. Treatment of psoriatic arthritis in a phase 3 randomised, placebo-controlled trial with apremilast, an oral phosphodiesterase 4 inhibitor. Ann Rheum Dis. 2014;73: 1020-1026.

44. Mease PJ, Goffe BS, Metz J, VanderStoep A, Finck B, Burge DJ. Etanercept in the treatment of psoriatic arthritis and psoriasis: a randomised trial. Lancet. 2000;356:385-390.

45. Mease PJ, Kivitz AJ, Burch FX, et al. Etanercept treatment of psoriatic arthritis: safety, efficacy, and effect on disease progression. Arthritis Rheum. 2004;50:2264-2272.

46. Antoni CE, Kavanaugh A, Kirkham B, et al. Sustained benefits of infliximab therapy for dermatologic and articular manifestations of psoriatic arthritis: results from the infliximab multinational psoriatic arthritis controlled trial (IMPACT). Arthritis Rheum. 2005;52:1227-1236.

47. Antoni C, Krueger GG, de Vlam K, et al; IMPACT 2 Trial Investigators. Infliximab improves signs and symptoms of psoriatic arthritis: results of the IMPACT 2 trial. Ann Rheum Dis. 2005;64:1150-1157.

48. Mease PJ, Gladman DD, Ritchlin CT, et al; Adalimumab Effectiveness in Psoriatic Arthritis Trial Study Group. Adalimumab for the treatment of patients with moderately to severely active psoriatic arthritis: results of a double-blind, randomized, placebo-controlled trial. Arthritis Rheum. 2005;52:3279-3289.

49. Genovese MC, Mease PJ, Thomson GT, et al. Safety and efficacy of adalimumab in treatment of patients with psoriatic arthritis who had failed disease modifying antirheumatic drug therapy. $J$ Rheumatol. 2007;34:1040-1050.

50. Gottlieb A, Menter A, Mendelsohn A, et al. Ustekinumab, a human interleukin 12/23 monoclonal antibody, for psoriatic arthritis: randomised, double-blind, placebo-controlled, crossover trial. Lancet. 2009;373: 633-640. 
51. Kavanaugh A, McInnes I, Mease P, et al. Golimumab, a new human tumor necrosis factor alpha antibody, administered every four weeks as a subcutaneous injection in psoriatic arthritis: twenty-four-week efficacy and safety results of a randomized, placebo-controlled study. Arthritis Rheum. 2009;60:976-986.

52. Mease P, Genovese MC, Gladstein G, et al. Abatacept in the treatment of patients with psoriatic arthritis: results of a six-month, multicenter, randomized, double-blind, placebo-controlled, phase II trial. Arthritis Rheum. 2011;63:939-948.

53. Baranauskaite A, Raffayová H, Kungurov NV, et al; RESPOND investigators. Infliximab plus methotrexate is superior to methotrexate alone in the treatment of psoriatic arthritis in methotrexate-naive patients: the RESPOND study. Ann Rheum Dis. 2012;71:541-548.

54. McInnes IB, Kavanaugh A, Gottlieb AB, et al; PSUMMIT 1 Study Group. Efficacy and safety of ustekinumab in patients with active psoriatic arthritis: 1 year results of the phase 3, multicentre, double-blind, placebo-controlled PSUMMIT 1 trial. Lancet. 2013;382:780-789.

55. McInnes IB, Sieper J, Braun J, et al. Efficacy and safety of secukinumab, a fully human anti-interleukin-17A monoclonal antibody, in patients with moderate-to-severe psoriatic arthritis: a 24-week, randomised, double-blind, placebo-controlled, phase II proof-of-concept trial. Ann Rheum Dis. 2014;73:349-356.

56. Mease PJ, Fleischmann R, Deodhar AA, et al. Effect of certolizumab pegol on signs and symptoms in patients with psoriatic arthritis: 24-week results of a phase 3 double-blind randomised placebo-controlled study (RAPID-PsA). Ann Rheum Dis. 2014;73:48-55.

57. Mease PJ, Genovese MC, Greenwald MW, et al. Brodalumab, an antiIL17RA monoclonal antibody, in psoriatic arthritis. $N$ Engl J Med. 2014;370:2295-2306.

58. Ritchlin C, Rahman P, Kavanaugh A, et al; PSUMMIT 2 Study Group. Efficacy and safety of the anti-IL-12/23 p40 monoclonal antibody, ustekinumab, in patients with active psoriatic arthritis despite conventional nonbiological and biological anti-tumour necrosis factor therapy: 6-month and 1-year results of the phase 3, multicentre, double-blind, placebo-controlled, randomised PSUMMIT 2 trial. Ann Rheum Dis. 2014;73:990-999.

59. Cutolo M, Myerson GE, Fleischmann RM, et al. Long-term (52-week) results of a phase 3, randomized, controlled trial of apremilast, an oral phosphodiesterase 4 inhibitor, in patients with psoriatic arthritis (PALACE 2). Arthritis Rheum. 2013;65:S346-S347.

60. Edwards CJ, Blanco FJ, Crowley J, Hu C, Stevens RM, Birbara CA. Long-term (52-week) results of a phase 3, randomized, controlled trial of apremilast, an oral phosphodiesterase 4 inhibitor, in patients with psoriatic arthritis and current skin involvement (PALACE 3). Arthritis Rheum. 2013;65:S132.

61. Wells AF, Edwards CJ, Adebajo AO, et al. Apremilast in the treatment of DMARD-naive psoriatic arthritis patients: results of a phase 3 randomized, controlled trial (PALACE 4). Arthritis Rheum. 2013;65: S3320-S3321.

62. Mease P, McInnes IB, Kirkham B, et al. Secukinumab, a Human anti-interleukin-17A monoclonal antibody. Arthritis Rheum. 2014;66: S423-S424.

63. McInnes IB, Mease PJ, Kirkham B, et al. Secukinumab, a human anti-interleukin-17A monoclonal Antibody, improves active psoriatic arthritis: 24 week efficacy and safety data from a phase 3 randomised multicentre, double-blind, placebo-controlled study using subcutaneous. Arthritis Rheum. 2014;66:2539.
64. Mease P, Gottlieb AB, Berman A, et al. A phase IIb, randomized, double-blind, placebo-controlled, dose-ranging, multicenter study to evaluate the efficacy and safety of clazakizumab, an anti-IL-6 monoclonal antibody, in adults with active psoriatic arthritis. Arthritis Rheum. 2014;66:S423.

65. Strand V, Mease PJ, McInnes IB, et al. Secukinumab, an anti-interleukin17A monoclonal antibody, improves physical function, quality of life and work productivity in patients with active psoriatic arthritis: results from a phase 3, randomized, controlled trial. Arthritis Rheum. 2014;66:S240-S241.

66. Donahue KE, Gartlehner G, Jonas DE, et al. Systematic review: comparative effectiveness and harms of disease-modifying medications for rheumatoid arthritis. Ann Intern Med. 2008;148:124-134.

67. van den Berg R, Baraliakos X, Braun J, van der Heijde D. First update of the current evidence for the management of ankylosing spondylitis with non-pharmacological treatment and non-biologic drugs: a systematic literature review for the ASAS/EULAR management recommendations in ankylosing spondylitis. Rheumatology. 2012;51: 1388-1396.

68. Kavanaugh A, Sanz LP, Gottlieb AB, et al. Long term improvements in physical function are associated with improvements in dactylitis, enthesitis, tender and swollen joint counts, and psoriasis skin involvement: results from a phase 3 study of ustekinumab in psoriatic arthritis patients. Arthritis Rheum. 2014;66:S688.

69. Kavanaugh A, Sanz LP, Gottlieb AB, et al. Efficacy and safety of ustekinumab in psoriatic arthritis patients with spondylitis and peripheral joint involvement: results from a phase 3 multicenter double-blind placebo-controlled study. Arthritis Rheum. 2014;66: S234.

70. Ritchlin C, Rahman P, Sanz LP, et al. Treatment effect of ustekinumab on fatigue in patients with psoriatic arthritis: results from PSUMMIT 2. Clin Exp Rheumatol. 2014;32:824.

71. Kavanaugh A, McInnes IB, Ritchlin CT, et al. Integrated safety of ustekinumab in psoriatic arthritis: 2 year follow-up from the psoriatic arthritis clinical development program. Arthritis Rheum. 2014;66: S686-S687

72. NICE Technology Appraisals TA313. Ustekinumab for Treating Active Psoriatic Arthritis; 2014. Available from: https://www.nice.org.uk/ guidance/ta313. Accessed May 20, 2014.

73. van der Heijde D, Robert BM, Landewé RB, et al. Secukinumab, a monoclonal antibody to interleukin-17A, provides significant and sustained inhibition of joint structural damage in active psoriatic arthritis regardless of prior TNF inhibitors or concomitant methotrexate: a phase 3 randomized, double-blind, placebo-controlled study. Arthritis Rheum. 2014;66:S424-S425.

74. Hart B, Lundh A, Bero L. Effect of reporting bias on meta-analyses of drug trials: reanalysis of meta-analyses. BMJ. 2012;344:d7202.

75. Coates LC, Navarro-Coy N, Brown SR, et al. The TICOPA protocol (tight control of psoriatic arthritis): a randomised controlled trial to compare intensive management versus standard care in early psoriatic arthritis. BMC Musculoskelet Disord. 2013;14:101.

76. Gottlieb AB, Armstrong AW. Psoriasis outcome measures: a report from the GRAPPA 2012 annual meeting. J Rheumatol. 2013;40: 1428-1433.
Psoriasis: Targets and Therapy

\section{Publish your work in this journal}

Psoriasis: Targets and Therapy is international, peer-reviewed, open access journal focusing on psoriasis, nail psoriasis, psoriatic arthritis and related conditions, identification of therapeutic targets and the optimal use of integrated treatment interventions to achieve improved outcomes and quality of life. The manuscript management system

\section{Dovepress}

is completely online and includes a very quick and fair peer-review system. Visit http://www.dovepress.com/testimonials.php to read real quotes from published authors. 